\title{
Fusion as the result of sperm-somatic cell interaction
}

\author{
M Mattioli, A Gloria, A Mauro, L Gioia and B Barboni \\ Department of Comparative Biomedical Sciences, University of Teramo, Piazza A. Moro, 45, 64100 Teramo, Italy \\ Correspondence should be addressed to A Gloria; Email: gloriaalessia@libero.it \\ B Barboni; Email: bbarboni@unite.it
}

\begin{abstract}
The research has been designed to investigate whether acrosome-reacted spermatozoa can fuse with somatic cells and to check whether this event may involve the molecular machinery implicated in the sperm-egg fusion. Boar spermatozoa were capacitated in vitro and then treated with A23187 to induce acrosome reaction and activate their fusogenic potential. Reacted spermatozoa, loaded with the membrane-permeant fluorescent dye calcein AM, were incubated with plated granulosa cells or cells derived from stable cell lines: CRFK, VERO, and ESK4. The fusion between spermatozoa and somatic cells was revealed by the diffusion of the fluorescent dye from the sperm to the cell as membrane fusion and cytoplasmic continuity between the two cells were established. The involvement of integrin $\alpha 6$ and tetraspanin CD9 in the process of fusion was assessed by carrying out the experiment in the presence of antibodies against these molecules. Moreover, the incidence of fusion displayed by the different cell types used was analyzed in relation to their content in the above molecules assessed by western blot and immunostaining. The role of CD9 was additionally investigated by using CD9-negative cells. The data presented demonstrate that boar spermatozoa can fuse with different somatic cell types derived from different species and the process requires the combined presence of both integrin and tetraspanin molecules on the cell plasma membrane.

Reproduction (2009) 138 679-687
\end{abstract}

\section{Introduction}

Fertilization in mammals requires the completion of several steps that begin with the deposition of the sperm into the female genital tract and end with sperm-egg membrane fusion, the culminating event that brings together paternal and maternal genomes and triggers the activation of embryo development.

Cell fusion is generally believed to be a rare event, restricted to specific cell types, which consists in the fusion of the membrane lipid bilayers with consequent cytoplasm mixing of two different cells. Membrane fusion occurs in animal systems at three different levels: viral-host cell fusion, intracellular vesicles fusion, and cell-cell fusion. Of these three contexts, cell-cell fusion is comparatively the most poorly understood process and the membrane factors involved are still far from clear despite the physiological relevance of this phenomenon. In the case of sperm-egg interaction, membrane fusion occurs after a long and complex series of sequential approaching interactions that assume the meaning of a highly selective process at the end of which only the spermatozoa, which are more suitable for fertilization, can reach the oocyte. The sperm encounters two layers surrounding the oocyte, the expanded cumulus and the zona pellucida (ZP), which must be crossed before sperm-egg fusion. At the ZP level, a rather complex molecular interaction occurs with the proteins of the ZP that triggers the acrosome reaction (AR) in the sperm cell (Podell et al. 1984, Florman \& Wassarman 1985, Wassarman 1987, 1990, Hardy \& Garbers 1994, Metz \& Palumbi 1996, Oehninger 2001, McCartney \& Lessios 2004). Reacted spermatozoa may then cross the ZP and enter the perivitelline space where the conclusive phase of the sperm-egg interaction is played, eventually ending in gamete membrane fusion and in the sperm components, including the nucleus, finally entering into the ooplasm (Yanagimachi 1994).

The process of cell-cell fusion involves three key events: 1) membrane recognition, mainly due to ligandreceptor binding; 2) membrane apposition, where membrane protein interactions bring the membranes close together; and 3) lipid bilayers mixing, involving the sequential fusion of the proximal and of the distal layers. At this point, cytoplasmic continuity between the two cells is established. The precise molecular mechanisms involved in this process have attracted the attention of many researchers, but the limitation of available material and the problems related to the study of protein-protein interactions have not allowed to definitively clarify this topic yet. However, experimental evidence indicates a list of potential candidates that may take part in cell fusion by acting on the two cell sides. Sperm proteins belonging to the ADAM family (a disintegrin and metalloprotease), particularly fertilin $\beta$ (ADAM2) and cyritestin (ADAM3), present on the sperm membrane, 
have been shown to play a central role in sperm-egg binding and fusion by interacting with specific ligands (integrins) on the egg membrane. Integrins are transmembrane $\alpha \beta$ heterodimers that play crucial roles in cell-cell adhesion, cell-extracellular matrix adhesion, and multiple signaling pathways. The integrin $\alpha 6 \beta 1$ was first proposed as the receptor for sperm on mouse egg by Almeida et al. (1995). Since then a number of reports have confirmed the expression of integrin $\alpha 6 \beta 1$ on the membrane of both gametes and the involvement of this protein in sperm-egg interaction (Chen \& Sampson 1999, Linfor \& Berger 2000, Barraud-Lange et al. 2007). Nevertheless, the immunoneutralization experiments aimed at blocking the function of this integrin have provided disparate results, according to the technique, enzymatic, chemical, or mechanical, used to remove the ZP (Almeida et al. 1995, Evans et al. 1997, Evans 1999). Moreover, oocytes from integrin $\alpha 6 \beta 1$-deficient mice showed normal binding and fusion with sperm, suggesting that integrin is not essential for gamete fusion in mice (Miller et al. 2000).

More recently, another surface protein, CD9, has been discovered to play an essential role in sperm-egg fusion in mouse as well as in other species (Chen et al. 1999, Kaji et al. 2000, Miyado et al. 2000, Le Naour et al. 2000, Zhu et al. 2002, Li et al. 2004, Zhou et al. 2009). The involvement of CD9, a member of the tetraspanin family, has been documented by the inhibition of spermegg fusion recorded in the presence of anti-CD9-specific antibodies, as well as by using egg of CD9-knockout mice in IVF systems. Ziyyat et al. (2006) have proposed a functional link between these two molecules suggesting that CD9 controls the membrane redistribution of surface proteins, including integrins, into clusters that may be necessary for sperm-egg interaction.

Interestingly, the proteins involved in membrane fusion, such as integrins and CD9, are widely diffused on the plasma membranes and are highly conserved. Many cell types, like granulosa cells (GC), express CD9 as well as integrin $\alpha 6 \beta 1$ associated on their membrane, just like the egg, and could sustain an interaction with sperm cells ending in cell-sperm fusion (Takao et al. 1999). The possibility that spermatozoa might interact with somatic cell types may provide new models to investigate the molecular basis of cell fusion. This might increase the investigation potential providing increased availability of biological material, different membrane protein arrangements, and the standardized membrane structure of specific cell lines. Moreover, an obvious potential exploitation of this sperm-cell interaction could be the development of reproducible and reliable tests to assess sperm-cell function and add further steps in the knowledge of the process of fertilization. The present research has therefore been designed to investigate whether acrosome-reacted spermatozoa can fuse with somatic cells of different origin. Moreover, the use of function-blocking antibodies and western blots' analysis have been carried out to assess whether this spermatozoa-cell fusion involves the same molecular machinery that is involved, as far as we know, in the sperm-egg fusion.

The data presented do show that boar spermatozoa can fuse with different somatic cell types derived from different species and that fusion requires the combined presence of integrins and tetraspanins.

\section{Results}

\section{Functional fusion assay}

Boar spermatozoa were capacitated in vitro and then exposed to A23187 to induce AR and activate their fusogenic potential. Freshly ejaculated spermatozoa displayed a percentage of spontaneous AR of 3.1 $\pm 1.5 \%$ (3.1 $\pm 0.5, n=100)$. The proportion of acrosomereacted spermatozoa at the end of the capacitating incubation was $13.2 \pm 4 \%$, while the percentage rose to $48.7 \pm 6.6 \%$ in the spermatozoa exposed to A23187 $(P \leq 0.001)$.

When A23187-reacted spermatozoa were added to cell preparations, a proportion of plated cells became intensely fluorescent (Fig. 1; right panel) due to the dye diffusion from fused sperm. When the functional fusion assay (FFA) was carried out by adding nonreacted spermatozoa (spermatozoa not exposed to A23187) to cultured cells, the percentage of fusion recorded never exceeded $2 \%$ and most of the cells were nonfluorescent even when fluorescent spermatozoa were close to them, as shown in Fig. 1 (left panel). The absence of fluorescence in these cells incubated together with acrosome-intact, calcein-loaded spermatozoa demonstrates that the dye does not leak from loaded spermatozoa and diffuse into plated cells, confirming that the simple presence or contact of loaded sperm with somatic cells does not result in cell fluorescence unless fusion takes place.

The incidence of cell fusion was clearly affected by the culture interval used to prepare plated cells (Fig. 2). After $4 \mathrm{~h}$ of culture, the cells, independently from the type, had just started to attach to the bottom of the coverglass chamber and retained a clear spherical shape, and low fusion rates were recorded when acrosome-reacted spermatozoa were added to these cells (VERO: $0.8 \pm 0.2$; ESK4: $0.73 \pm 0.2$; CRFK: $4.76 \pm 0.68$; GC: $3.73 \pm 0.61$ ).

When the culture of plated cells was carried out for $24 \mathrm{~h}$, cells were attached to the bottom of coverglass displaying a poliedric shape and the incidence of cell fusion markedly increased after exposure to reacted spermatozoa (VERO: $3.2 \pm 0.9$; ESK4: $3.8 \pm 0.81$; CRFK: 20.6 \pm 1.5 ; GC: $9.86 \pm 2.9$ ).

After a culture interval of $48 \mathrm{~h}$, the cells were still attached but extremely flattened on the coverglass, and low fusion incidence was recorded after acrosome-reacted sperm addition (VERO: 0.58 \pm 0.01 ; ESK4: $0.68 \pm 0.1$; CRFK: $0.83 \pm 0.15$; GC: $1.5 \pm 0.5$ ). 


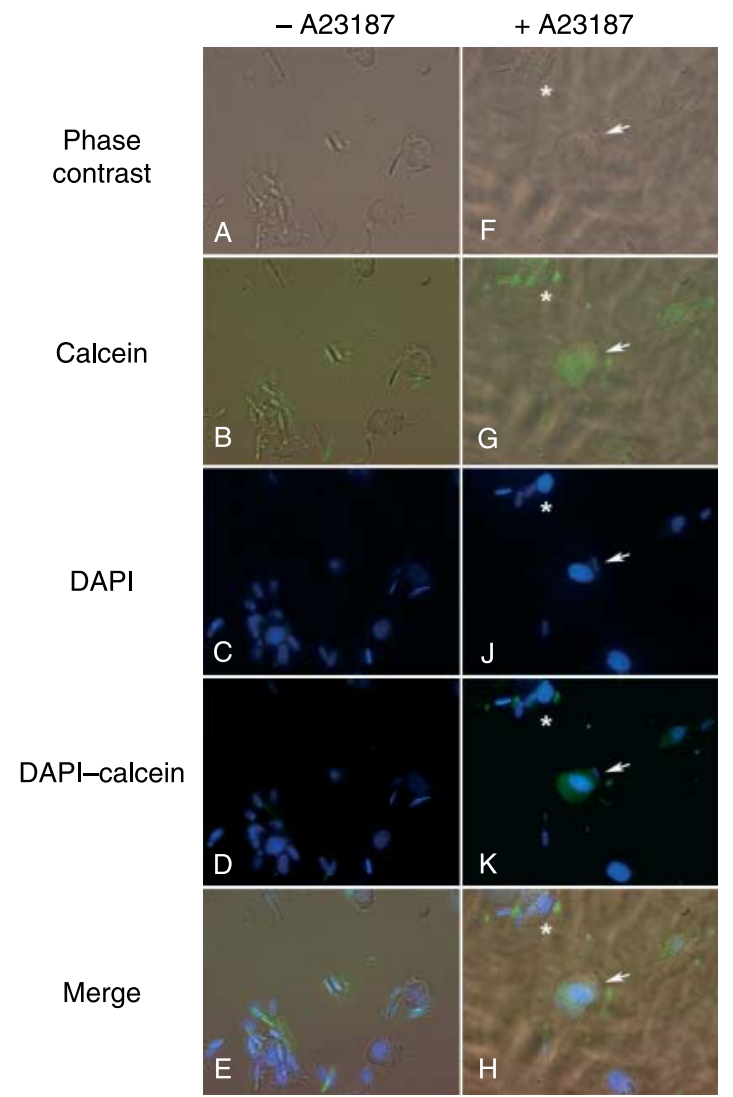

Figure 1 Representative epifluorescence images of sperm-cells fusion. Capacitated sperm cells, not exposed (left panel: A-E) or exposed (right panel: $\mathrm{F}-\mathrm{H}$ ) to $\mathrm{A} 23187$, were loaded with fluorescent calcein $\mathrm{AM}$ (green) and then co-incubated for $1 \mathrm{~h}$ with cell lines as described in Materials and Methods. Cell nuclei were identified with DAPI (C-E and $\mathrm{J}-\mathrm{H}$; blue). (B, D, and E) Absence of fusion between spermatozoa and CRFK cells. No somatic cell shows green fluorescence, and calcein is retained in the cytoplasm of intact sperm cells. (G, K, and $\mathrm{H}$ ) Example of sperm-CRFK cells fusion (arrow). The green fluorescent dye has diffused into a somatic cell that fused with the sperm and entered into cytoplasmic continuity. The asterisk shows an example of the absence of sperm-cell fusion. The green fluorescence is visible only inside the intact spermatozoa even though they are close to the cell. (Magnification: $400 \times$ ).

According to these preliminary results, only cells cultured for $24 \mathrm{~h}$ were used for the further FFA experiments.

\section{Role of CD9 and integrin $\alpha 6$ in cell fusion process}

The following experiments, aimed at analysing the molecular mechanism of sperm-cell fusion by using specific function-blocking antisera, were carried out exclusively with CRFK cells cultured for $24 \mathrm{~h}$ for their higher fusion potential. Zona-free metaphase II (MII) oocytes $(n=50)$ were used as the reference cells naturally involved in cell fusion, and CD9 negative cells were used to further test the role of this specific molecule in the process of fusion.

As shown in Figs 3 and 4, anti-CD9 and anti-integrin $\alpha 6$ antibodies were able to significantly $(P \leq 0.001)$ reduce both sperm-egg and sperm-CRFK cell fusion. The percentage of sperm-egg fusion (i.e. the percentage of oocytes with at least one fused spermatozoon) was reduced from $83 \%$ in the absence of antibodies to $6.2 \%$ and to $10 \%$ in the presence of anti-CD9 and anti-integrin $\alpha 6$ antibodies respectively.

Similarly, the percentage of fusion was reduced in CRFK cells $(P \leq 0.001)$ from values of $22 \%$ in the absence of antibodies to 6.3 and $2.7 \%$ when anti-CD9 and antiintegrin $\alpha 6$ were added respectively. By contrast, the addition of nonspecific rat anti-goat IgG did not affect the fusion rate in both oocytes and CRFK cells (79 and $20.8 \%$ respectively $P>0.05$ ).

When FFA was carried out with Raji, the special cell type that does not express CD9, the incidence of fusion was as low as $0.5 \%(P \leq 0.001$; Fig. 4$)$.

\section{CD9 and integrin $\alpha 6$ expression in somatic cells}

Western blot analysis was carried out in the different cell types used for FFA in order to assess whether the different fusion capacity of these somatic cells was related to their integrin $\alpha 6$ and CD9 contents on the plasma membrane.

As shown in Fig. 5, CD9 protein was differently expressed in the cells types during 4, 24 and $48 \mathrm{~h}$ of culture. CD9, detected as a single $24 \mathrm{kDa}$ protein band (Fig. 5A), was clearly expressed, at $4 \mathrm{~h}$ of culture, in CRFK cells (densitometric values (d.v.): $0.135 \pm 0.03$ ) and, to a lesser extent, in GC and VERO cells (d.v.: $0.077 \pm 0.02$ and $0.075 \pm 0.01$ respectively). On the contrary, in ESK4 and in negative control Raji cells, the detected levels were very low (d.v.: $0.025 \pm 0.002$ and $0.025 \pm 0.001$ respectively; Fig. $5 \mathrm{~A}$ and $\mathrm{B}$ ). CD9 protein expression levels strongly increased after $24 \mathrm{~h}$ of
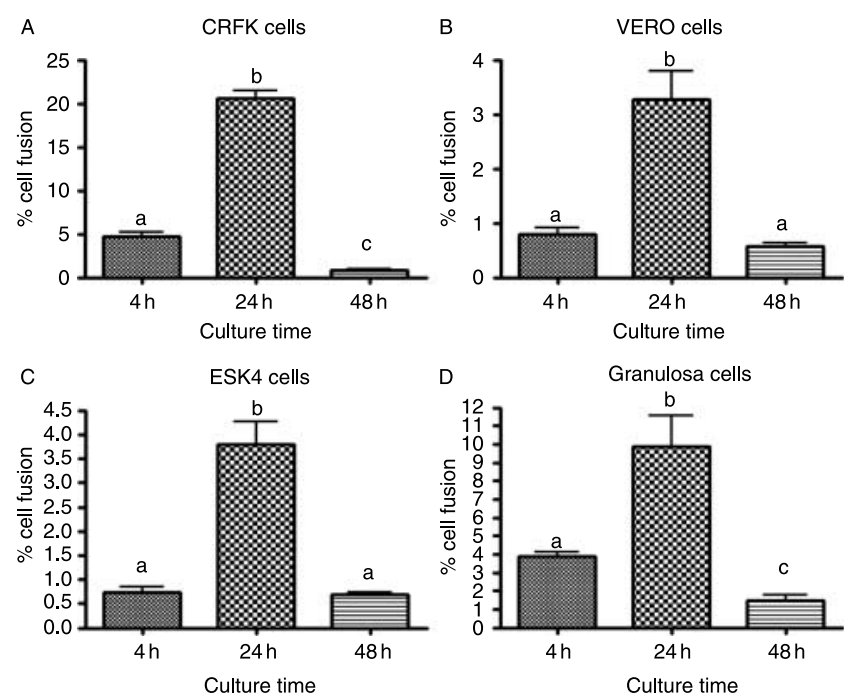

Figure 2 Functional fusion assay analyses in (A) CRFK, (B) VERO, (C) ESK4, and (D) granulosa cells (GC) after 4, 24, and 48 h of culture. $\mathrm{a}, \mathrm{b}, \mathrm{c}$ Values statistically different $(P<0.05)$ during culture time within cell types. 


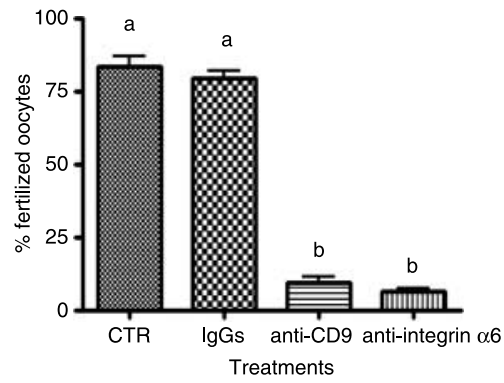

Figure 3 Percentage values of zona-free mature oocytes fertilized (IVF) in the absence (CTR) and in the presence of nonspecific IgGs or after the pre-incubation with specific anti-CD9 or anti-integrin $\alpha 6$ antibodies.

${ }_{\mathrm{a}, \mathrm{b}}$ Values statistically different $(P<0.05)$ between treatments.

culture only in CRFK (d.v.: $0.39 \pm 0.01)$ and in GC cells (d.v.: $0.20 \pm 0.02$ ), but the expression was slightly downregulated after $48 \mathrm{~h}$ (d.v.: CRFK $0.19 \pm 0.01$ and GC $0.13 \pm 0.01)$. Differently, in the remaining cell types after 24 and $48 \mathrm{~h}$ of culture, the CD9 protein expression was not modulated and their quantitative levels were similar (d.v.: VERO $0.1 \pm 0.005$ and $0.06 \pm 0.001$; ESK4 $0.025 \pm 0.001$ and $0.025 \pm 0.002$; Raji $0.025 \pm 0.001$ and $0.03 \pm 0.02$ ) to those observed after $4 \mathrm{~h}$ of culture (Fig. 5A and B).

Conversely to the increased CD9 expression recorded after $24 \mathrm{~h}$ of culture in CRFK and GC, the results of immunoblotting obtained about integrin $\alpha 6$ expression demonstrated that this protein, in all the cell types cultured for $24 \mathrm{~h}$, was expressed at similar quantitative levels (d.v.: 0.25 \pm 0.05 ; Fig. 6). Unchanged levels of the integrin $\alpha 6$ protein in these cells were observed at 4 and $48 \mathrm{~h}$ (data not shown).

Immunostaining using anti-CD9 and anti-human integrin $\alpha 6$ antibodies allowed to identify the distribution of the above molecules on the plasma membranes of the different cell types analyzed. While integrin $a 6$ was similarly distributed on the membrane of all the cell types tested (data not shown), CD9 membrane

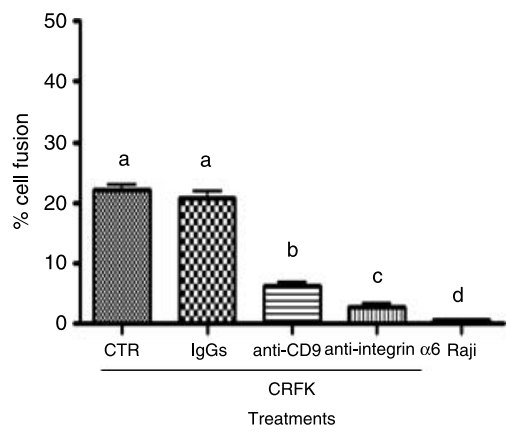

Figure 4 Percentage values of sperm-cell fusion recorded in CRFK after $24 \mathrm{~h}$ of culture in the absence (CTR) and in the presence of nonspecific $\gamma$-globulins (IgGs) or after the pre-incubation with anti-CD9 or antiintegrin $\alpha 6$ antibodies. The incidence of fusion was also evaluated with the CD9-negative cells (Raji) cultured for 24 h. ${ }^{\text {a,b,c,d }}$ Values statistically different $(P<0.05)$ between treatments. distribution were dependent on the cell type analyzed. In fact, as shown in Fig. 7, CD9 was clearly detectable on the membrane of CRFK cells, was revealed by a faint signal in GC, while it was nearly absent in the remaining cell types as well as in the CD9 negative cells (Raji).

\section{Discussion}

The results of this research show that calcein-loaded spermatozoa can transfer the dye to somatic cells once the fusogenic machinery is activated by AR. Spermatozoa can express their fusogenic potential only after AR. The requirement of AR for the activation of the

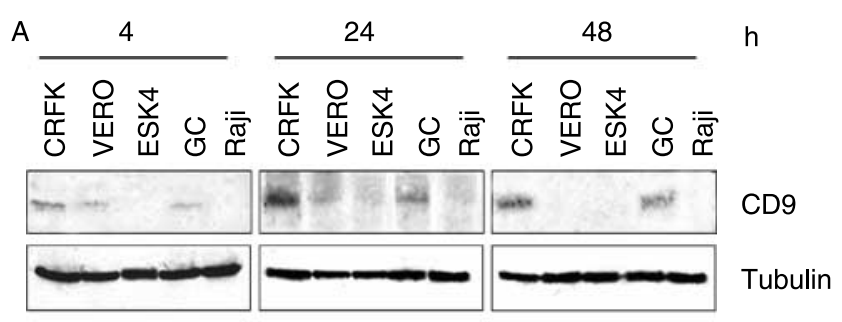

B
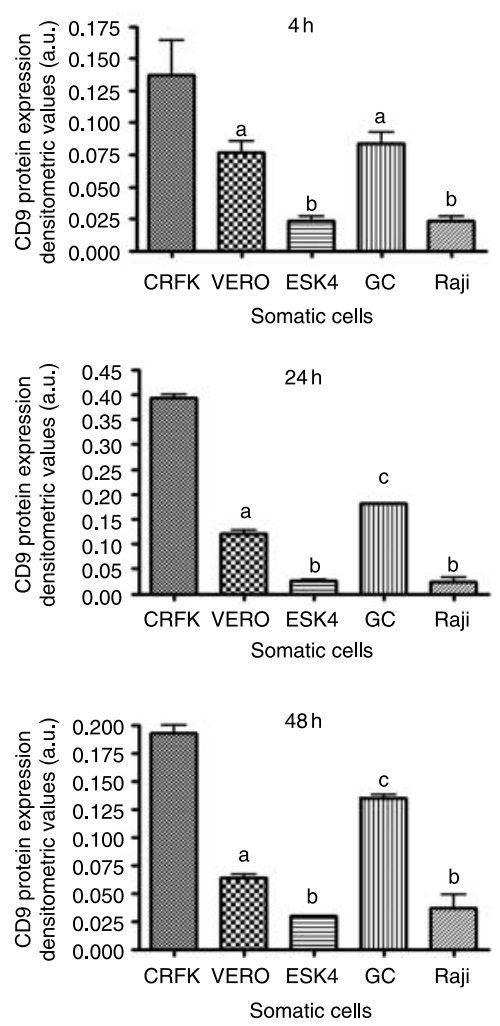

Figure 5 Analysis of CD9 protein expression. (A) Representative images of immunoblotting of CD9 and tubulin proteins expression on the different cells types after 4, 24, and 48 h of culture. Raji cells were used as negative control for the CD9 protein expression. The experiments were repeated three times with similar results. (B) Densitometric evaluation of proteins expression levels normalized on the basis of tubulin expression. ${ }^{\mathrm{a}, \mathrm{b}, \mathrm{c}}$ Values statistically different $(P<0.05)$ between the cell types. 
A

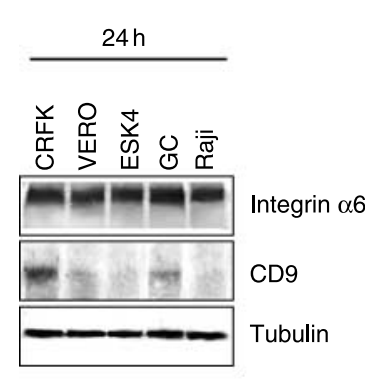

B

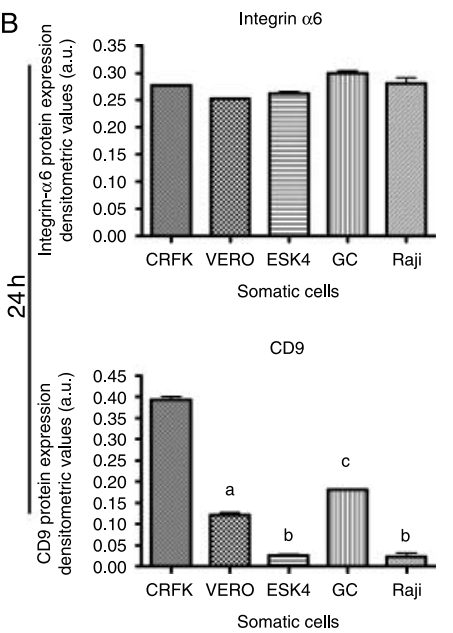

Figure 6 Expression of integrin $\alpha 6$ and CD9. (A) Representative images of immunoblotting of CD9, integrin $\alpha 6$, and tubulin proteins expression on the different cells types after $24 \mathrm{~h}$ of culture.

The experiments were repeated three times with similar results.

(B) Densitometric evaluation of proteins expression levels normalized on the basis of tubulin expression. ${ }^{\mathrm{a}, \mathrm{b}, \mathrm{c}}$ Values statistically different $(P<0.05)$ between the cell types.

fusogenic part of the equatorial segment of the sperm head is well known (Flechon et al. 1986, Baldi et al. 1996), and here we show that AR conditions the fusion with other cell types too. Specific structural and spatial rearrangements of fertilin $\beta$ at the equatorial segment occur after AR, thus activating the fusogenic potential of the spermatozoa. Dye transfer, in fact, potentially does not occur when nonreacted sperm (sperm not treated with A23187) are added to cell preparations. In this case, in fact, somatic-plated cells closely contacting fully fluorescent sperm do not acquire any detectable fluorescence. Moreover, this finding allows to exclude that fluorescent dye may leak out of loaded sperm cells and then diffuse into the cells.

Interestingly, the incidence of sperm-cell fusion was markedly affected by the cell preparations. In fact, besides the different fusion capacity of the cell types tested, attributable to their membrane's biochemical composition, as discussed later, a higher fusion efficiency was recorded in cells cultured for $24 \mathrm{~h}$ compared with cell preparations cultured for 4 or $48 \mathrm{~h}$. Fusion is likely to result from the combination of several factors, from the presence of the molecules involved in cell-cell interaction, to the shape of the cells and therefore the amount of surface exposed to the sperm, to the vigor of sperm motility that may condition the first attachment phases of sperm on the plated cells.

Western blot analysis shows low levels of CD9 in cells cultured for $4 \mathrm{~h}$, thus providing a potential explanation of the low fusion incidence recorded in these preparations. Similarly, the levels of these molecules in cells cultured for $48 \mathrm{~h}$ are lower compared with that recorded in $24 \mathrm{~h}$ cultured cells. The drop of fusion efficiency

recorded in $48 \mathrm{~h}$ cultured cells may also depend on the tridimensional conformation of the cells in culture, which, at this time, are markedly flattened on the bottom of the culture chamber and may be less exposed to wandering spermatozoa than $24 \mathrm{~h}$ cultured cells. However, little doubt exists that physical impediment exerted by spermatozoa conditions the potential interaction between sperm and plated cells. Even in the best experimental conditions adopted, the incidence of somatic cell fused with spermatozoa never exceeded $22 \%$. Preliminary experiments (data not shown) demonstrated that such a level could not be increased using higher sperm concentrations, since sperm themselves with their tendency to agglutinate creates with their tails a rather dense network that limits the access to plated cells.

The present investigation demonstrates that boar sperm can fuse with somatic cells belonging to the same species as well as with cells derived from other species.
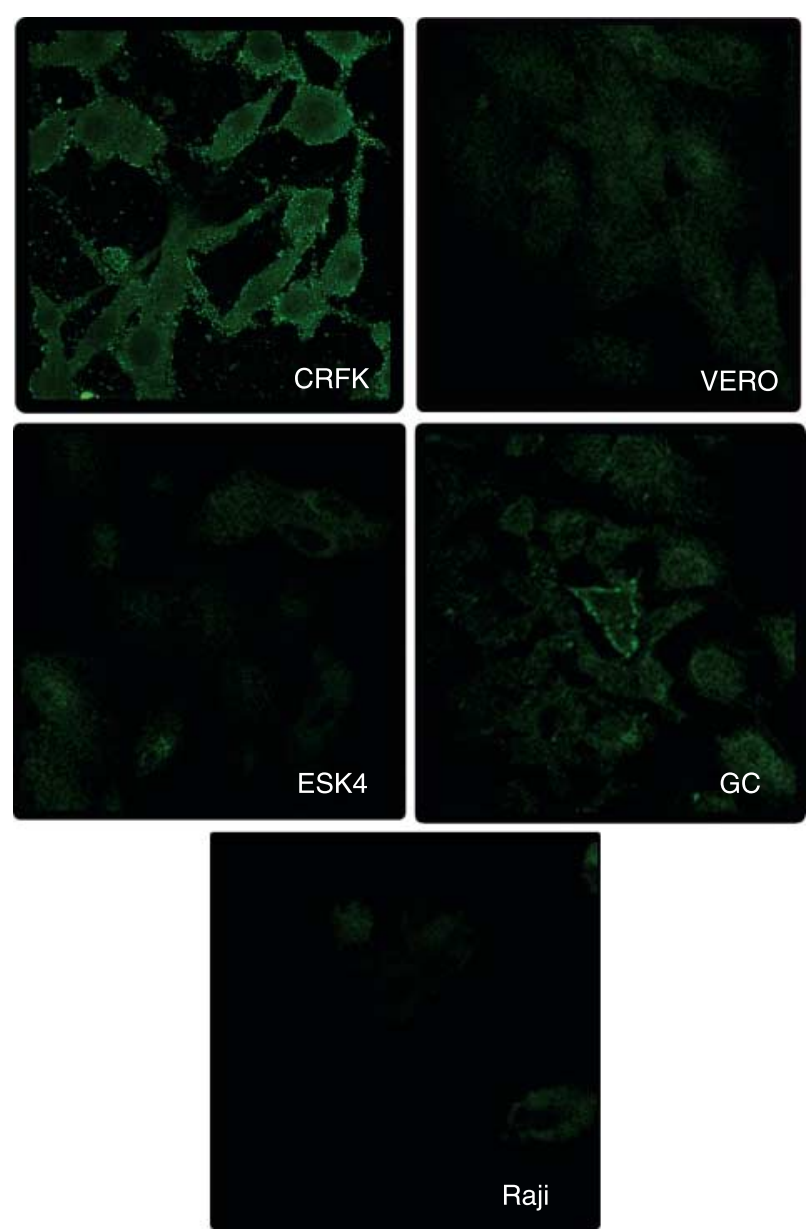

Figure 7 Representative confocal laser microscope images of CD9 protein expression on different cell types cultured for $24 \mathrm{~h}$. Immunolabelings were performed as described in Materials and Methods. (Magnification: $400 \times$ ). 
A number of reports have described sperm interaction with somatic cells, from the nonspecific binding with tissue that is not naturally interacting with the sperm, such as the sperm fusion with leucocytes (Ashida \& Scotfield 1987) and the case reported by Almeida et al. (1995), where F9 mouse embryonal carcinoma cells bound spermatozoa with an intensity proportional to the amount of integrins on the plasma membrane, to the well-known binding of spermatozoa to the oviduct cells, which is likely to play a physiological role in the selection and/or capacitation of spermatozoa that are retained in the oviduct reservoir, waiting for the ovulated oocytes (Hunter 1990).

However, in none of these cases, the binding was consistently followed by sperm-cell fusion. This is not surprising as the fusogenic potential of spermatozoa, naturally activated by $A R$, had not been previously switched on in the above situations. In our investigation, such a condition was achieved by treating in vitro capacitated spermatozoa with the $\mathrm{Ca}$ ionophore A23187, which resulted in proportion of reacted sperm close to $50 \%$.

If cell-cell binding is a pre-requisite for fusion, the simple cell-cell contact is not a condition sufficient to drive fusion that, in fact, can occur only when apposing cell membranes have the proper molecular machinery. The present work has been designed to assess whether the process of sperm fusion with somatic cells involves the same molecular machinery involved in sperm-egg fusion. Sperm-egg fusion is mediated by a series of molecular interactions between sperm fertilin, egg integrins, and members of the tetraspanin family (Wassarman et al. 2001, Primakoff \& Myles 2002). In the work of Almeida et al. (1995) and in more recent investigations (Ziyyat et al. 2006), sperm-egg binding and fusion are considered as two sequential phases, the first being a pre-requisite but nondeterminant for final fusion. $\alpha 6 \beta 1$ integrin has been suggested to mediate the binding of fertilin $\beta$ (ADAM2) and cyritestin (ADAM3), two members of the ADAM family (a disintegrin and metalloprotease) expressed on sperm (Chen \& Sampson 1999, Chen et al. 1999, Takahashi et al. 2001, Tomczuk et al. 2003), and fusion might occur following a second protein interaction or simply as a result of the former adhesion. However, the role of integrin in the process of sperm-egg fusion is controversial. The use of function-blocking antibodies has given conflicting results, mostly conditioned by the technique adopted to prepare zona-free oocytes (Almeida et al. 1995, Evans et al. 1997, Evans 1999). The inhibitory effects of the anti-integrin antibody on sperm-egg interaction has, in fact, supposed to derive on the protease treatment used to prepare zona-free eggs responsible for the loss of function and/or the alteration of some egg membrane proteins involved in gamete interaction.

Moreover, the finding that oocytes derived from integrin-negative mice can be successfully fertilized (Miller et al. 2000) suggests that this molecule does not play an essential role in the process of sperm-egg fusion in the mouse, although its participation in the process cannot be excluded. At present, available data suggest that the integrins may take part in a membrane protein web that marks the fertilization site in the egg membrane. The molecular redundancy that characterizes many fundamental processes, such as fertilization, is probably responsible for the difficult interpretation of the experimental results. Similarly, an appropriate distribution of interacting molecules may be required on the plasma membrane of the apposing cells for fusion to occur (Tarone et al. 1993, Takahashi et al. 2001, Ziyyat et al. 2006).

Immunoneutralization experiments carried out with a specific function-blocking antibody anti-integrin $\alpha 6$ suggest that this protein is involved in sperm-egg fusion as well as in spermatozoa-cell fusion. In this last particular case, the inhibitory effect exerted by antiintegrin antibody could not be attributed to any enzymatic treatment since cell preparation did not involve the use of any enzyme.

Even in the case of sperm-cell fusion, integrins may represent an important anchoring site for the sperm disintegrins, thus creating the pre-requisite for fusion or, in addition, they could directly take part in the following phases of fusion, but this is presently unclear.

A marked inhibitory influence on cell fusion was recorded when anti-CD9 antibody was added to the FFA system, in agreement with the finding of Zhu et al. (2002). Our results confirm these data and extend the involvement of this factor to sperm fusion with other cell types. Interestingly enough, the levels of expression of this protein and its presence on the cell plasma membrane were positively related to fusion capacity of the cells tested, and the absence of fusion recorded in the negative control CD9-negative cells confirms the central role played by this molecule.

The combination of the results of immunoneutralization, immunoblotting, and immunolocalization suggests that both integrins and CD9 are required for somatic cells fusion. Both molecules are most likely involved in clustering membrane proteins involved in fusion, thus affecting their efficacy, but their relative influence turns out to be different. Integrins are, in fact, present at similar levels in all the cell types tested, while CD9, with levels of expression changing markedly from one cell type to the other, assumes the meaning of the fusionconditioning factor. CRFK and GC, for their high CD9 concentration in the plasma membrane, are in fact superior to the other cell types for studying sperm-cell interaction.

The finding that sperm-cell fusion seems to involve two of the major molecules that support sperm-egg fusion suggests that sperm-cell fusion may provide an useful model for the understanding of the mechanisms of fertilization. Moreover, specific cell lines, with good fusogenic activity, such as CRFK, may be used to develop 
reliable test for assessing sperm function and to replace the hamster zona-free oocytes test with more standardized cell assays.

Understanding the molecular machinery residing beyond membrane fusion is a relevant issue also with respect to cell therapy, gene targeting, and, more in general, to the identification of the more suitable route to gain access to the cell and to condition or to correct its functions.

\section{Materials and Methods}

\section{Chemical agents and antibodies}

Chemicals were of the purest analytical grade. FCS was purchased from Gibco BRL. Calcein AM was purchased from Molecular Probes Inc (Eugene, OR, USA). Rat anti-CD9 (KMC8.8) MAB and peroxidase-conjugated anti-rat IgG were from Santa Cruz Biotechnologies (Santa Cruz, CA, USA), whereas rat anti-human integrin $\alpha 6(\mathrm{GoH} 3) \mathrm{MAB}$ was from Chemicon International Inc., Temecula, CA, USA, anti-goat $\operatorname{lgG}$ and monoclonal anti- $\alpha$-tubulin clone B-5-1-2 were from Sigma. Nitrocellulose was purchased from Hybon C Extra, Amersham Pharmacia.

All the other reagents and hormones used for these experiments were purchased from Sigma Chemical Co.

\section{Sperm preparation}

Semen samples were collected by the gloved-hand technique from five boars of proven fertility, 3 years old, of Landrace genetic lines. The seminal plasma was removed by centrifugation through a two-step discontinuous gradient of 35 and $70 \%$ isotonic Percoll (Harrison et al. 1996) to select motile cells. After removal of the supernatant layers, the resultant loose pellet was resuspended in residual $70 \%$ Percoll and washed by centrifugation at $800 \mathrm{~g}$ for $10 \mathrm{~min}$ in Dulbecco's phosphate buffer with $0.4 \%$ BSA. The pellet was then diluted in capacitation medium (tissue culture medium (TCM) 199 supplemented with $10 \%$ FCS, calcium lactate $2.25 \mathrm{mM}$, sodium pyruvate $1.25 \mathrm{mM}$, and glucose $13.9 \mathrm{mM}$ ) and incubated for $2 \mathrm{~h}$ at a final concentration of $1 \times 10^{8}$ spermatozoa (spz)/ml at $38.5^{\circ} \mathrm{C}$ in $5 \% \mathrm{CO}_{2}$ humidified atmosphere. At the end of capacitation, spermatozoa were incubated for $20 \mathrm{~min}$ in the above-described medium supplemented with A23187 $(1 \mu \mathrm{M})$ and calcein AM $(4 \mu \mathrm{M})$. The ionophore A23187 was used to trigger AR and activate sperm fusogenic potential. The incidence of AR before and after A23187 treatment was evaluated in each sperm sample by FITC-PSA staining performed according to Barboni et al. (1995) and Mattioli et al. (1996). The membrane-permeant calcein AM was used to load the sperm cells. This dye can freely diffuse inside the cells, where it is transformed in a polar molecule that cannot cross back the intact membrane.

Following calcein loading, spermatozoa were thoroughly washed by centrifugation before addition to zona-free MII oocytes (IVF: positive control) or to the different cell preparations.

\section{Oocytes collection, in vitro maturation}

Ovaries of pre-pubertal gilts were collected at a local slaughterhouse and transported to the laboratory within $1 \mathrm{~h}$, kept at a temperature of $25^{\circ} \mathrm{C}$. After washing in saline, the ovaries were mechanically dissected under sterile conditions in Dulbecco's phosphate buffer with $0.4 \%$ BSA and $70 \mathrm{mg} / \mathrm{l}$ kanamycin. Ovarian healthy follicles, $4-5 \mathrm{~mm}$ in diameter, selected on the basis of their translucent appearance, good vascularization, and compactness of their granulosa layer, were opened and cultured as everted follicles according to Mattioli et al. (1989). In brief, the follicles were put in Petri dishes containing $2 \mathrm{ml}$ of TCM 199 medium supplemented with $10 \%$ FCS, $70 \mathrm{mg} / \mathrm{l}$ kanamycin, insulin-transferrinselenium $10 \mu \mathrm{l} / \mathrm{ml}, 1 \mu \mathrm{g} / \mathrm{ml}$ porcine-LH, and $1 \mu \mathrm{g} / \mathrm{ml} \mathrm{FSH}$ (USDA-pLH-B1 and USDA-pFSH-B1, kindly provided by the National Pituitary Hormone Distribution Program, NIDDK-NIH, Bethesda, MD, USA), opened, and turned inside out. Everted follicles were then placed on a stainless grid to avoid contact with the Petri dish bottom. After $44 \mathrm{~h}$ of culture of the cumulus-oocytes complexes collected, the oocyte was denuded of expanded cumulus mass in Hepes-TCM 199 with hyaluronidase $0.1 \%(\mathrm{w} / \mathrm{v})$, and only the oocytes with extruded polar body (MII stage) were selected; ZP was removed with pronase $0.25 \%$ (PBS) using a fine glass pipette on a warmed stage at $38.5^{\circ} \mathrm{C}$ before fusion assay experiments.

\section{Cells preparation}

Cell fusion experiments were carried out using standard cell lines or cells isolated from ovarian follicles. CRFK (cat kidney cells), VERO (African green monkey cells), ESK4 (embryonic swine kidney; BS CL 42), and Raji (CD9-negative B cells: Raji Human Burkitt lymphoma) cell lines were purchased from IZS of Brescia. GC were collected from pig ovarian follicles (4-5 mm in diameter) according to Mattioli et al. (1989).

All cell samples were washed twice by centrifugation (800 $g$ for $5 \mathrm{~min}$ ) in Dulbecco's phosphate buffer with $0.4 \%$ BSA and then resuspended in minimal essential medium supplemented with $10 \%$ FCS, 1 mmol glutamine $/ \mathrm{l}$, and $70 \mu$ g gentamycin $/ \mathrm{ml}$. Cell suspension $\left(1 \times 10^{4}\right.$ cells $\left./ 2 \mathrm{ml}\right)$ was then plated in a chambered coverglass (a special chamber with a fine coverglass at the bottom purchased from NUNC, Naperville, IL, USA) and cultured at $37.5{ }^{\circ} \mathrm{C}$ in $5 \% \mathrm{CO}_{2}$.

To define the best experimental conditions for the study of sperm-cell interaction, the different cell types were cultured for different intervals $(4,24$, and $48 \mathrm{~h})$ and, at the end of these culture intervals, the chambers were washed to remove cells in suspension or loosely attached and the remaining plated cells were used for the FFA as following described.

\section{Functional fusion assay}

FFA is based on the hypothesis that when a loaded spermatozoon fuses with another cell the dye diffuses and this cell becomes fluorescent.

AR-induced spermatozoa were added to plated cells to a final concentration of $1 \times 10^{7} \mathrm{spz} / \mathrm{ml}$. After $1 \mathrm{~h}$ of coincubation, plated cells were washed twice in Hepes-TCM 
199 and stained with 4'6-diamidino-2-phenylindole (DAPI; $10 \mu \mathrm{g} / \mathrm{ml}$ ) to count the total cell number. The fusion capacity of spermatozoa, expressed as percentage of calcein-positive cells/total cells (DAPI positive cells), was evaluated by using an epifluorescence microscope (Nikon Eclipse 600) equipped for u.v. and FITC (EX 330-380; DM 400; BA 420 and EX 465495; DM 505; BA 515-555 respectively). Each fusion assay also included a negative control: calcein-loaded, acrosome-intact sperm (sperm capacitated but not treated with A23187), to exclude the possibility of dye leakage from nonfused sperm. Moreover, experiments of fusion were also carried out with zona-free mature oocytes (IVF: positive control).

In order to test whether sperm-cell fusion involves both CD9 and integrin $\alpha 6$, two major molecules supposed to be involved in the process of sperm-egg fusion (Podell et al. 1984, Wassarman 1987), the cell preparations as well as the oocytes, were pre-incubated for $1 \mathrm{~h}$ with specific antibodies anti-human integrin $\alpha 6(50 \mu \mathrm{g} / \mathrm{ml}$; according to Ziyyat et al. 2006) and antiCD9 $(50 \mu \mathrm{g} / \mathrm{ml}$; according to Miller et al. 2000), and then washed before exposure to calcein-loaded spermatozoa. Plated cells and eggs were also challenged for fusion in the presence of nonspecific $\gamma$-globulins (anti-goat IgG $50 \mu \mathrm{g} / \mathrm{ml}$, $\gamma$-globulin) or without any $\gamma$-globulins (control, CTR).

Finally, FFA was also carried out using Raji cells that do not express CD9 (Ikeyama et al. 1993, Shaw et al. 1995), in order to further investigate the role played by the tetraspanin in the process of cell fusion.

\section{Western blot analysis}

CRFK, VERO, ESK4, GC, and Raji cells were plated and cultured as previously described for 4,24 , and 48 h. Raji cells were used in the western blot experiments as negative control of CD9 protein expression.

The cells were then lysed in $300 \mu \mathrm{l}$ of $2 \%$ SDS containing $2 \mathrm{mM}$ phenylmethylsulphonyl fluoride, $2 \mathrm{mM}$ sodium orthovanadate, $10 \mathrm{mM}$ sodium fluoride, $10 \mu \mathrm{g} / \mathrm{ml}$ leupeptin, $10 \mu \mathrm{g} / \mathrm{ml}$ antipain, $100 \mathrm{units} / \mathrm{ml}$ aprotinin as phosphatase and protease inhibitors and sonicated for $30 \mathrm{~s}$. Protein content was evaluated by Lowry method (Lowry et al. 1951). Equal amount of proteins ( $50 \mu \mathrm{g} / \mathrm{sample}$ ) was then separated by 8 and $12 \%$ SDS-PAGE (Laemmly 1970) and electrophoretically transferred onto nitrocellulose (Hybond C Extra, Amersham Pharmacia Biotech, Inc.) according to standard procedures (Towbin et al. 1979). After staining with Ponceau $S$, the membranes were blocked for $1 \mathrm{~h}$ at room temperature (RT) with Tris buffer saline (TBS: $20 \mathrm{mM}$ Tris $\mathrm{pH} 7.6,150 \mathrm{mM}$ ) plus 5\% (w/v) nonfat dry milk, and following primary antibodies were used according to the manufacturer's instructions: anti-CD9 (1:500); anti-integrin a6 (1:5000); monoclonal anti- $\alpha$-tubulin clone B-5-1-2 $(1: 3000)$. Membranes were washed with TBS containing $0.05 \%(\mathrm{v} / \mathrm{v})$ Tween 20 and incubated for $1 \mathrm{~h}$ with peroxidaseconjugated anti-mouse IgG or anti-rat IgG (1:3000). The signals were detected by using the ECL Western Blot analysis system (Amersham Bioscience). The quantitative densitometric analysis of proteins, normalized on $\boldsymbol{\alpha}$-tubulin expression, was carried out with the Advanced Image Data Analyzer (Rai Test; $\mathrm{GMBH}$, Straubenhardt, Germany).

\section{Immunofluorescence}

GC, CRFK, VERO, ESK4, and Raji cells cultured for $24 \mathrm{~h}$ were fixed in $4 \%$ buffered paraformaldehyde (PBS pH 7.4) at $4{ }^{\circ} \mathrm{C}$ for $1 \mathrm{~h}$. After washing for $5 \mathrm{~min}$ with PBS on oscillating plate, the samples were incubated for $1 \mathrm{~h}$ at RT with normal goat serum $(1: 20)$, and then treated one sample with a affinity-purified rat MAB KMC8.8 raised against CD9 and another sample with a affinity rat $M A B \mathrm{GoH} 3$ against human integrin $\alpha 6,200 \mu \mathrm{g} / \mathrm{ml}$, for $1 \mathrm{~h}$ at RT. Control specimens were prepared by omitting the primary antibody. After two washing, cells were incubated with FITC-conjugated goat anti-rat $\lg (1: 200)$ for $1 \mathrm{~h}$ at RT in darkness, washed twice, and then analyzed by Bio-Rad laserscanning confocal microscope (Radiance 2000 IK-2) equipped with an excitation wavelength of $488 \mathrm{~nm}$ and the detector set for an emission wavelength of $525 \mathrm{~nm}$ (magnification: 400×).

\section{Statistical analysis}

All experiments were carried out at least five times in independent trials (5 replicates/group per experiment). All data were expressed as mean ( \pm s.D). The results of treatments were compared by one-way ANOVA followed, when required, by Tukey's test (Orion Software Development, Version 2.0, Longmont, CO, USA). Differences were considered significant for $P<0.05$ values.

\section{Declaration of interest}

The authors declare that there is no conflict of interest that would prejudice the impartiality of this scientific work.

\section{Funding}

This work was supported by grant from MIUR-PRIN 2006.

\section{Acknowledgements}

The authors thank Dr Taschini Sergio (Semenitaly srl, Modena, Italy) for sperm cells and Palucci Ottavio (Department of Comparative Biomedical Sciences, University of Teramo, Italy) for cell cultures' assistance.

\section{References}

Almeida EA, Houvila AP, Sutherland AE, Stephens LE, Calarco PG, Shaw LM, Mercurio AM, Sonnenberg A, Primakoff P, Myles DG et al. 1995 Mouse egg integrin $\alpha 6 \beta 1$ functions as a sperm receptors. Cell 81 1095-1104.

Ashida ER \& Scotfield VL 1987 Lymphocyte major histocompatibility complex-encoded class II structures may act as sperm receptors. PNAS 84 3395-3399.

Baldi E, Luconi M, Bonaccorsi L, Krausz C \& Forti G 1996 Human sperm activation during capacitation and acrosome reaction: role of calcium, protein phosphorylation and lipid remodelling pathways. Frontiers in Bioscience 1 189-205.

Barboni B, Mattioli M \& Seren E 1995 Influence of progesterone on boar sperm capacitation. Journal of Endocrinology 144 13-18. 
Barraud-Lange V, Naud-Barriant N, Saffar L, Gattegno L, Ducot B, Drillet AS, Bomsel M, Wolf JP \& Ziyyat A 2007 a6 $\beta 1$ integrin expressed by sperm is determinant in mouse fertilization. BMC Developmental Biology 7102.

Chen H \& Sampson NS 1999 Mediation of sperm-egg fusion: evidence that mouse egg $\alpha 6 \beta 1$ integrin is the receptor for sperm fertilin beta. Chemistry \& Biology 6 1-10.

Chen MS, Tung KS, Coonrod SA, Takahashi Y, Bigler D, Chang A, Yamashita Y, Kincade PW, Herr JC \& White JM 1999 Role of the integrinassociated protein CD9 in binding between sperm ADAM 2 and the egg integrin a6ß1: implications for murine fertilization. PNAS 96 11830-11835.

Evans JP 1999 Sperm disintegrins, egg integrins, and other cell adhesion molecules of mammalian gamete plasma membrane interactions. Frontiers in Bioscience 4 D114-D131.

Evans JP, Kopf GS \& Schultz RM 1997 Characterization of the binding of recombinant mouse sperm fertilin beta subunit to mouse eggs: evidence for adhesive activity via an egg beta1 integrin-mediated interaction. Developmental Biology 187 79-93.

Flechon JE, Harrison RAP, Flechon B \& Escaig J 1986 Membrane fusion events in the $\mathrm{Ca}^{2+}$ /ionophore-induced acrosome reaction of ram spermatozoa. Journal of Cell Science 81 43-63.

Florman HM \& Wassarman PM 1985 O-linked oligosaccharides of mouse egg ZP3 account for its sperm receptor activity. Cell 41 313-324.

Hardy DM \& Garbers DL 1994 Species-specific binding of sperm proteins to the extracellular matrix (zona pellucida) of the egg. Journal of Biological Chemistry 269 19000-19004.

Harrison RA, Ashwort PJ \& Miller NG 1996 Bicarbonate/CO 2 , an effector of capacitation, induced a rapid and reversible change in the lipid architecture of boar sperm plasma membrane. Molecular Reproduction and Development 45 378-391.

Hunter RH 1990 Fertilization of pig eggs in vivo and in vitro. Journal of Reproduction and Fertility Supplement 40 211-226.

Ikeyama S, Koyama M, Yamaoko M, Sasada R \& Miyake M 1993 Suppression of cell motility and metastasis by transfection with human motility-related protein (MRP-1/CD9) DNA. Journal of Experimental Medicine 177 1231-1237.

Kaji K, Oda S, Shikano T, Ohnuki T, Uematsu Y, Sakagami J, Tada N, Miyazaki S \& Kudo A 2000 The gamete fusion process is defective in eggs of CD9-deficient mice. Nature Genetics 24 279-282.

Laemmly UK 1970 Cleavage of structural proteins during the assembly of the head of bacteriophage T4. Nature 227 680-685.

Li Y-H, Hou Y, Ma W, Yuan J-X, Zhang D, Sun Q-Y \& Wang W-H 2004 Localization of CD9 in pig oocytes and its effects on sperm-egg interaction. Reproduction 124 151-157.

Linfor J \& Berger T 2000 Potential role of alphav and beta1 integrins as oocyte adhesion molecules during fertilization in pigs. Journal of Reproduction and Fertility 120 65-72.

Lowry OH, Rosebrough NJ, Farr AL \& Randall RJ 1951 Protein measurement with the Folin phenol reagent. Journal of Biological Chemistry 193 265-275.

Mattioli M, Bacci ML, Galeati G \& Seren E 1989 Developmental competence of pig oocytes matured and fertilized in vitro. Theriogenology 31 1201-1207.

Mattioli M, Barboni B, Lucidi P \& Seren E 1996 Identification of capacitation in boar spermatozoa by chlortetracycline staining. Theriogenology 45 373-381.

McCartney MA \& Lessios HA 2004 Adaptive evolution of sperm bindin tracks egg incompatibility in neotropical sea urchins of the genus Echinometra. Molecular Biology and Evolution 21 732-745.

Metz EC \& Palumbi SR 1996 Positive selection and sequence rearrangements generate extensive polymorphism in the gamete recognition protein bindin. Molecular Biology and Evolution 13 397-406.

Miller BJ, Georges-Labouesse E, Primakoff P \& Myles DG 2000 Normal fertilization occurs with eggs lacking the integrin $\alpha 6 \beta 1$ and is CD9dependent. Journal of Cell Biology 149 1289-1296.
Miyado K, Mekada E \& Kobayashi K 2000 A crucial role of tetraspanin, CD9 in fertilization. Tanpakushitsu Kakusan Koso 45 1728-1734.

Le Naour F, Rubinstein E, Jasmin C, Prenant M \& Boucheix C 2000 Severely reduced female fertility in CD9-deficient mice. Science $\mathbf{2 8 7}$ 319-321.

Oehninger S 2001 Molecular basis of human sperm-zona pellucida interaction. Cells, Tissues, Organs 168 58-64.

Podell SB, Moy GW \& Vacquier VD 1984 Isolation and characterization of a plasma membrane fraction from sea urchin sperm exhibiting species specific recognition of the egg surface. Biochimica et Biophysica Acta 778 25-37.

Primakoff P \& Myles DG 2002 Penetration, adhesion, and fusion in mammalian sperm-egg interaction. Science 296 2183-2185.

Shaw AR, Domanska A, Mak A, Gilchrist A, Dobler K, Visser L, Poppema S, Fliegel L, Letarte M \& Willett BJ 1995 Ectopic expression of human and feline CD9 in a human B cell line confers beta 1 integrin-dependent motility on fibronectin and laminin substrates and enhanced tyrosine phosphorylation. Journal of Biological Chemistry 270 24092-24099.

Takahashi Y, Bigler D, Ito Y \& White JM 2001 Sequence-specific interaction between the disintegrin domain of mouse ADAM 3 and murine eggs: role of beta1 integrin-associated proteins CD9, CD81, and CD98. Molecular Biology of the Cell 12 809-820.

Takao Y, Fujiwara H, Yamada S, Hirano T, Maeda M, Fujii S \& Ueda M 1999 CD9 is expressed on the cell surface of human granulosa cells and associated with integrin a6ß1. Molecular Human Reproduction 5 303-310.

Tarone G, Russo MA, Hirsch E, Odorisio T, Altruda F, Silengo L \& Siracusa G 1993 Expression of beta 1 integrin complexes on the surface of unfertilized mouse oocyte. Development 117 1369-1375.

Tomczuk M, Takahashi Y, Huang J, Murase S, Mistretta M, Klaffky E, Sutherland A, Bolling L, Coonrod S, Marcinkiewicz C et al. 2003 Role of multiple beta1 integrins in cell adhesion to the disintegrin domains of ADAMs 2 and 3. Experimental Cell Research 290 68-81.

Towbin H, Staehelin T \& Gordon J 1979 Electrophoretic transfer of proteins from polyacrylamide gels to nitrocellulose sheets: procedure and some applications. PNAS 76 4350-4354.

Wassarman PM 1987 The biology and chemistry of fertilization. Science 235 553-560.

Wassarman PM 1990 Profile of a mammalian sperm receptor. Development $1081-17$.

Wassarman PM, Jovine L \& Litscher ES 2001 A profile of fertilization in mammals. Nature Cell Biology 3 E59-E64.

Yanagimachi R 1994 Mammalian fertilization. In The Physiology of Reproduction, pp 189-317. Eds E Knobil \& JD Neill. New York: Raven Press.

Zhou GB, Liu GS, Meng QG, Liu Y, Hou YP, Wang XX, Li N \& Zhu SE 2009 Tetraspanin CD9 in bovine oocytes and its role in fertilization. Journal of Reproduction and Development 55 305-308.

Zhu GZ, Miller BJ, Boucheix C, Rubinstein E, Liu CC, Hynes RO, Myles DG \& Primakoff P 2002 Residues SFQ (173-175) in the large extracellular loop of CD9 are required for gamete fusion. Development 129 1995-2002.

Ziyyat A, Rubinstein E, Monier-Gavelle F, Barraud V, Kulski O, Prenant M, Boucheix C, Bomsel M \& Wolf JP 2006 CD9 controls the formation of clusters that contain tetraspanins and the integrin $\alpha 6 \beta 1$, which are involved in human and mouse gamete fusion. Journal of Cell Science $119416-424$.

Received 24 July 2008

First decision 29 September 2008

Revised manuscript received 28 May 2009

Accepted 7 July 2009 